\title{
Lentiviral vector-mediated $R B M 5$ overexpression downregulates EGFR expression in human non-small cell lung cancer cells
}

\author{
Zhenzhong Su', Jinzhi Yin', Lijing Zhao², Ranwei Li ${ }^{3}$, Hong Liang ${ }^{4}$, Jie Zhang ${ }^{1}$ and Ke Wang ${ }^{1 *}$
}

\begin{abstract}
Background: RNA binding motif 5 (RBM5) is a tumor suppressor gene that modulates apoptosis through the regulation of alternative splicing of apoptosis-related genes. Our previous studies suggested that RBM5 expression was negatively correlated with the expression of epidermal growth factor receptor (EGFR) in non-small cell lung cancer (NSCLC) tissues. This study was aimed at determining whether RBM5 is able to regulate EGFR expression.

Methods: Both in vitro and in vivo studies were carried out to determine the effect of RBM5 on the expression of EGFR. Lentiviral vector-mediated RBM5 overexpression was employed in lung adenocarcinoma cell line A549. A549 xenograft mice were treated with recombinant RBM5 plasmid carried by attenuated Salmonella typhi Ty21a. Real-time quantitative polymerase chain reaction and Western blot were carried out to detect RBM5 and EGFR expression.
\end{abstract}

Results: Both in vivo and in vitro studies indicated that the expression of EGFR mRNA and protein was decreased significantly in the RBM5 overexpression group compared to control groups as shown by real-time PCR and Western blot analysis. We identified that RBM5 overexpression inhibited EGFR expression both in A549 cells and in A549 xenograft mice model.

Conclusions: Our study demonstrated that EGFR expression is regulated by RBM5 in lung adenocarcinomas cells either in a direct or indirect way, which might be meaningful with regards to target therapy in lung cancer.

Keywords: RNA binding motif 5, Epidermal growth factor receptor, Non-small cell lung cancer, Lentiviral vector, A549, Xenograft mice model

\section{Background}

Lung cancer is one of the most common malignant tumors and remains the leading cause of cancer death both in males and females globally [1]. Among all lung cancer subtypes, non-small cell lung cancer (NSCLC) accounts for approximately $87 \%$ of all lung cancer cases, and has a poor prognosis; the overall five-year survival rate is $18.2 \%$ [2]. Molecularly, NSCLC development is believed to be initiated by the activation of oncogenes or inactivation of tumor suppressor genes [3].

Epidermal growth factor receptor (EGFR) (also known as $H E R-1$ or Erb1) is a cell-surface receptor belonging to

\footnotetext{
* Correspondence: kewangm1@hotmail.com

'Department of Respiratory Medicine, The Second Affiliated Hospital of Jilin University, No.218 Ziqiang Street, Nanguan District, Changchun, Jilin 130041 China

Full list of author information is available at the end of the article
}

the $\operatorname{ErbB}$ tyrosine kinase receptor family, which also includes HER-2/neu (ErbB2), HER-3 (ErbB3), and HER-4 (ErbB4). EGFR activation is associated with cell apoptosis, proliferation, angiogenesis, invasion, and metastasis, which plays an important role in carcinogenesis and tumor progression in human epithelial cancers, including NSCLC [4]. These actions are accomplished through activation of the RAS-RAF-MEK-ERK and PI3K-AKTmTOR pathways [5]. EGFR and PI3K initiate malignant neoplastic transformation via a combinatorial genetic network composed of other pathways, including the Tor, Myc, G1 Cyclins-Cdks, and Rb-E2F pathways [6], and drive cells through the restriction point of late $\mathrm{G}(1)$ into $S$ phase [7]. A series of anticancer agents directly targeting EGFR were developed and proved to be effective [8-13], but the clinical benefits of EGFR-TKIs are limited by primary or 
acquired resistance [14]. Therefore, EGFR inhibition by an upper regulator seems to be more attractive. Yet the EGFR upstream regulatory mechanisms are still not well understood. Further insights into important molecular regulators of EGFR are needed for the development of novel therapeutics.

RNA-binding motif protein 5 (RBM5) (also known as LUCA-15 or H37) maps to the human chromosomal locus $3 \mathrm{p} 21.3$, which is strongly associated with lung cancer [15]. It is reported to be downregulated in $73 \%$ of primary NSCLC specimens [16] and is also found in other human cancers. However, the precise mechanism by which $R B M 5$ mediated tumor suppression still remains to be clarified. Present studies are mostly focused on the regulation of apoptosis by the alternative splicing of correlated genes, such as Bax, Bcl-2, cleaved caspase3, caspase-9, and P53 [17-21]. Only a few researchers noticed another mechanism of negative regulation of cell proliferation, inducing cell cycle arrest in G1 by downregulating cyclin $A$ and phosphorylated $R B$ expression [17], which might also be involved in the malignant neoplastic transformation initiated by the EGFR and PI3K signaling pathway. These observations draw our interest in regard to the relationship between RBM5 and EGFR. We conducted a series of investigations to clarify the relationship between $R B M 5$ and an important regulator of cell proliferation, EGFR. We detected RBM5 and EGFR expression in 120 paired resected NSCLC tumor tissues and adjacent normal tissues in a previous study, which suggested that the RBM5 expression was negatively correlated with the expression of EGFR in NSCLC tissues [22]. Afterwards, we inhibited EGFR expression in the lung adenocarcinoma cell line NCI-H1975 using small interfering RNA, and found that RBM5 expression was not directly regulated by $E G F R$ in non-smoker-related lung adenocarcinomas [23]. Herein, we hypothesized that inhibition of EGFR in lung adenocarcinomas might be achieved via $R B M 5$ overexpression. The objective of this study was to assess whether forced RBM5 expression in lung adenocarcinoma cell line A549 cells and A549 xenografts could suppress the expression of EGFR, which would suggest that one of the mechanisms of potential tumor suppressor activity of RBM5 in NSCLC is initiated via the inactivation or inhibition of EGFR.

\section{Methods}

\section{Cell culture}

Human lung adenocarcinoma cell line A549 cells were purchased from the Chinese Academy of Medical Sciences (Beijing, China). Cells were grown in Roswell Park Memorial Institute (RPMI) 1640 supplemented with $10 \%$ fetal bovine serum (Gibco, Grand Island, United States), and maintained at $37^{\circ} \mathrm{C}$ in a humidified $5 \% \mathrm{CO}_{2}$ atmosphere.

\section{Lentiviral vectors construction and lentivirus infection}

Lentiviral vectors containing green fluorescence protein $(G F P)$ were employed in order to achieve high efficiency of introduction and subsequent stable expression of RBM5 in A549 cells. Recombined $p G C-L V$-GV287-GFP vector with the RBM5 (NM_005778) gene ( $L V-R B M 5$ ) and $p G C-L V-G V 287-G F P$ with a scrambled control sequence ( $L V-G V 287)$ were constructed by Genechem Company (Genechem, Shanghai, China). A549 cells were then infected with the above lentiviral vectors. A total of $5 \times 10^{5}$ A549 cells were seeded in a six-well cell plate and further incubated for 12 hours to reach $30 \%$ confluent, and then infected with LV-RBM5 (RBM5 overexpression group), LV-GV287 (negative control group), and no infection (non-transfected control group) by replacing the infection medium containing recombinant vectors at a multiplicity of infection (MOI) of 20 plaque-forming units (p.f.u.) per cell. Plates were then incubated for 24 hours prior to having their media changed to fresh, virus-free media. Three days later, the GFP density contained by lentivirus was detected to evaluate the efficiency of infection, and cells were harvested for Western blot and real-time quantitative polymerase chain reaction (RTqPCR) analysis.

\section{Establishment of A549 xenografts}

The use of animals in this study was in accordance with animal care guidelines, and the protocol was approved by Jilin University Animal Care Committee. A549 xenografts were established and the RBM5 gene was delivered into xenografts by attenuated Salmonella according to a previous study [19]. Briefly, BALB/c athymic nude female mice $(\mathrm{nu} / \mathrm{nu})$; between four and five-weeks-old) were purchased from the Institute of Zoology, Chinese Academy of Sciences (Beijing, China). A549 cells ( $1 \times$ $10^{7}$ ) were suspended in $100 \mu \mathrm{l}$ PBS and injected subcutaneously into the right flank region of nude mice.

Competent Salmonella enterica serovar typhimurium cells (competence) (obtained from the China-Japan Union Hospital of Jilin University, Jilin, China) were mixed with $1 \mu \mathrm{g}$ GV287-RBM5 or $1 \mu \mathrm{g}$ GV287 plasmids and cooled for 15 minutes on ice. The plasmids were electro-transfected into the competence under the conditions as follows: capacitance $=25 \mu \mathrm{F}$, voltage $=1.25 \mathrm{kV}$ $(12.5 \mathrm{kV} / \mathrm{cm})$. Then the recombinant attenuated salmonellae were quickly transferred into Luria-Bertani (LB) agar medium for proliferation at $37^{\circ} \mathrm{C}$ and stored at $-80^{\circ} \mathrm{C}$.

The tumor-bearing mice were randomly divided into three groups (six mice per group) at day 21 after cell injection. The mice were treated at day 28 and 35, respectively, through a tail vein as follows: (a) control group (50 $\mu \mathrm{l} \mathrm{PBS);} \mathrm{(b)} \mathrm{negative} \mathrm{control} \mathrm{group} \mathrm{(attenuated}$ 
Salmonella-carrying GV287) (10 ${ }^{8}$ colony-forming units (CFU) per $50 \mu \mathrm{l}$ PBS); (c) RBM5 overexpression group (attenuated Salmonella-carrying GV287-RBM5) $\left(10^{8} \mathrm{CFU}\right.$ per $50 \mu \mathrm{l}$ PBS). The mice were sacrificed on day 42 and the tumors were removed. One part of the tumor was fixed in Trizol ${ }^{\text {mi }}$ reagent (Invitrogen, Carlsbad, United States) for RT-qPCR, and another part was immediately snap-frozen in liquid nitrogen for Western blot analysis.

\section{Protein extraction and Western blot}

Total protein from both tumor tissues and cultured cells was extracted according to a previous study [22]. Briefly, protein concentration was measured by the Protein Assay Kit (Bio-Rad Laboratories, Richmond, United States). Equal amounts of protein samples $(30 \mu \mathrm{g})$ were separated by $8 \%$ SDS-PAGE and transferred onto poly (vinylidene fluoride) (PVDF) membranes (Millipore, Boston, United States). The membranes were treated with trisbuffered saline and Tween-20 solution (Sigma, California, United State) (TBST) containing $50 \mathrm{~g} / \mathrm{L}$ skimmed milk at room temperature for one hour, and incubated overnight at $4^{\circ} \mathrm{C}$ with a monoclonal antibody against RBM5 (Santa Cruz Biotechnology, California, United States) or EGFR (Proteintech Group, Chicago, United States).The mouse monoclonal antibody against $\beta$-actin (Proteintech Group, Chicago, United States) was used as a housekeeping control gene. Membranes were washed three times for 10 minutes with TBST and incubated with horseradish peroxidase-conjugated secondary antibodies (Proteintech Group, Chicago, United States) at a dilution of 1:500 for one hour at room temperature. Membranes were washed three times for 10 minutes with TBST, and bands were detected using an Amersham ECL Plus Western Blotting Detection Reagents (General Electric Company, Fairfield, United States).The protein levels were quantified by densitometry using Quantity One software (BioRad Laboratories, Richmond, United States).

\section{RNA extraction and real-time quantitative polymerase chain reaction}

Total RNA was extracted using Trizol reagent (Invitrogen, California, United States) according to the manufacturer's instructions. The ratio of absorbance at 260 and $280 \mathrm{~nm}$ (A260/280) was used to assess RNA purity and quantity. First-strand cDNA was generated using M-MLV Reverse Transcriptase (Promega, Madison, United States) and Oligo(dT) primers (Sangon Biotech, Shanghai, China) according to the manufacturer's instructions. Primers were made by Genechem (Genechem, Shanghai, China). Selected primer sequences included RBM5 forward 5'CCATCACAGAGAGCGATATTCG-3', RBM5 reverse 5'-CGGCTTACACCTGTTTTCCTC -3', EGFR forward 5'-ATGAGATGGAGGAAGACGG -3', EGFR reverse 5'-
CGGCAGGATGTGGAGAT-3', glyceraldehyde-3-phosphate dehydrogenase (GAPDH) forward $5^{\prime}$-TGACTTC AACAGCGACACCCA-3', and GAPDH reverse 5'CACCCTGTTGCTGTAGCCAAA-3'.

RT-qPCR was carried out using a Thermal Cycler Dice Real Time System (TaKaRa, Osaka, Japan) using Prime Script $^{\text {tu }}$ RT Master Mix (TaKaRa, Osaka, Japan). A twostep cycling condition was used for EGFR, RBM5, and GAPDH as follows: $95^{\circ} \mathrm{C}$ for 30 seconds followed by 40 cycles of $95^{\circ} \mathrm{C}$ for five seconds, and then $60^{\circ} \mathrm{C}$ for 30 seconds. A dissociation curve was generated for all three genes using the following conditions: $95^{\circ} \mathrm{C}$ for 15 seconds, $55^{\circ} \mathrm{C}$ for 30 seconds, and then $95^{\circ} \mathrm{C}$ for 15 seconds. The expression levels of the RBM5 and $E G F R$ genes were normalized to the internal control $G A P D H$, respectively, to obtain the relative threshold cycle $(\Delta \mathrm{Ct})$, and the relative expression between control A549 cells and infected cells was calculated using the comparative Ct $(\Delta \Delta \mathrm{Ct})$ method $(\Delta \Delta \mathrm{Ct}=\Delta \mathrm{Ct}$ of control cells $-\Delta$ Ct of infected cells ) or 2- $\Delta \Delta \mathrm{CT}$.

\section{Statistical analysis}

All experiments were performed at least in triplicate. All data were presented as means \pm standard deviation (SD). Statistical significance was determined by analysis of $\mathrm{t}$ test using SPSS version 17.0 (SPSS Inc., Chicago, United States). A $P$ value of less than 0.05 was considered statistically significant.

\section{Results}

\section{Infection efficiency of lentivirus vectors}

In order to achieve high efficiency of introduction and subsequent stable expression of RBM5 in A549 cells, we tried to import this gene by infecting A549 cells with $R B M 5$ lentiviral vectors containing GFP. The recombinant lentivirus vector $L V$-RBM5 was successfully constructed and infected A549 cells. The stably infected A549 cells expressed GFP after infection by the lentiviral vectors at different MOIs. GFP expression was detected three days after infection using fluorescence microscopy. The efficiency of the infection (averaged proportion of GFP-expressing cells on the total cell count) was approximately $80 \%$ at an MOI of 20 (Figure 1). Consequently, an MOI of 20 was chosen for the next steps of this study.

\section{Overexpression of RBM5 in A549 cells infected with lentiviral vectors}

RT-qPCR analysis demonstrated that the relative expression level of RBM5 mRNA was markedly increased in the RBM5 overexpression group $(13.32 \pm 2.16)$, compared with that in the negative control group $(1.00 \pm$ $0.09)$ and the non-transfected control group $(0.65 \pm 0.07$; $P<0.01$; Figure 2A). There was no statistical difference 
A

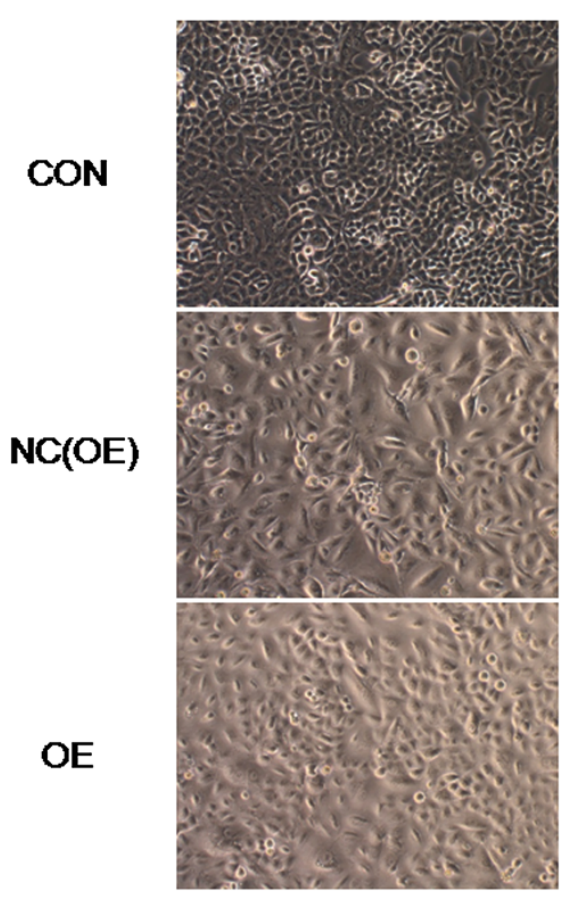

B
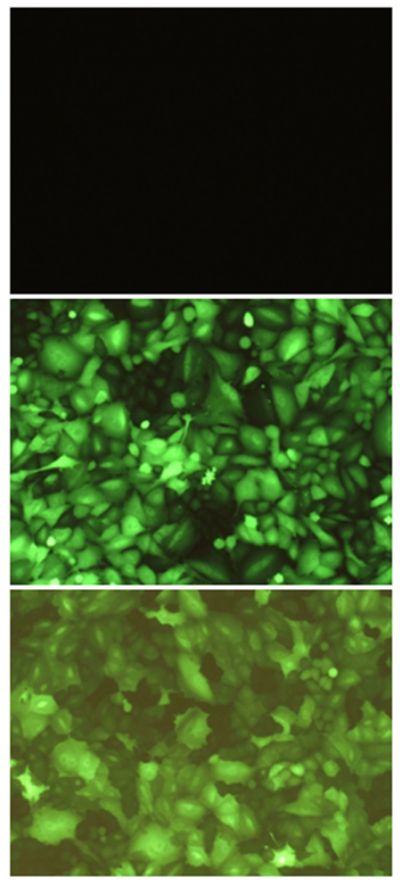

Figure 1 Infection efficiency of LV-RBM5 in A549 cells by GFP detection (100x). Lentiviral vector-mediated RBM5 expression was visualized by fluorescence microscopy three days after infection. Comparing the assessment in a bright field with the assessment in fluorescent field revealed an infection efficiency of over $80 \%$. A, bright field; B, fluorescent field; CON, control group with no transfection; NC(OE), negative control group transfected with GFP lentiviral vectors LV-GV287; OE, RBM5 overexpression group transfected with GFP lentiviral vectors LV-RBM5.

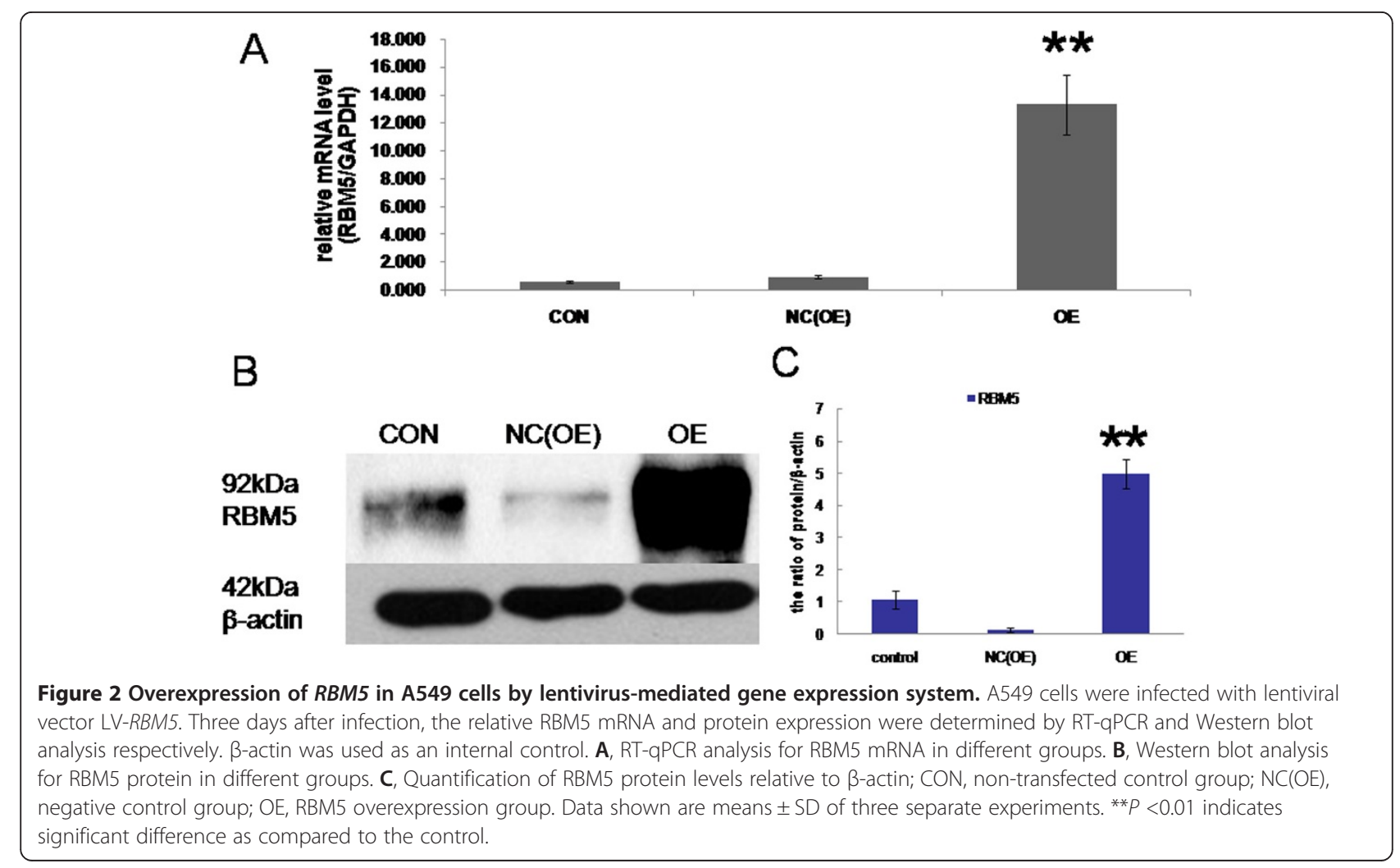


of RBM5 mRNA expression between the negative control and the non-transfected control $(P>0.05)$. Furthermore, the effectiveness of the lentiviral infection of $L V$-RBM5 was also confirmed by Western blot analysis. The protein expression of RBM5 in A549 cells was significantly higher in the $R B M 5$ overexpression group than that in the control groups (Figure 2B).

\section{Overexpression of RBM5 inhibits EGFR expression in A549 cells}

To explore whether $R B M 5$ is able to directly regulate EGFR expression, we examined EGFR mRNA by RTqPCR, and EGFR protein by Western blot analysis in A549 cells infected by different lentiviral vectors. As seen in Figure 3A, compared to negative control group and non-transfected control group, cells in the RBM5 overexpression group showed a significant decrease in EGFR expression (by $28.5 \%$ and $26.6 \%$, respectively; $P<0.001$ and $P<0.001$, respectively). Additionally, Western blot analysis showed that the protein expression of EGFR in the RBM5 overexpression group was significantly lower than that in the control groups (Figure 3B).
Suppression of EGFR expression by RBM5 overexpression in A549 xenograft tumors

To further test our hypothesis, the mice model of A549 xenograft was established as described in the Methods section. To ensure that the recombinant attenuated salmonellae-carrying plasmids preferentially localized in the xenograft tumors, the kinetics of bacterium distribution in the xenograft tumor and different organs of the tumor-bearing mice were monitored in a previous study [18]. At the 28th and 35th day after implantation, the tumor-bearing mice were treated with attenuated Salmonella-carrying plasmid through a tail vein. The mice were sacrificed 42 days after implantation and the tumors were removed to monitor the tumor sizes and to determine RBM5 and EGFR expression by RT-qPCR and Western blot analysis. H\&E staining were performed to observe histopathological performance on A549 xenografts. We observed that the mRNA and protein expression of RBM5 were significantly increased in the $R B M 5$ overexpression group as compared to those in control groups, while EGFR expression was decreased significantly in the RBM5 overexpression group as compared to those in control groups (Figure 4). H\&E staining

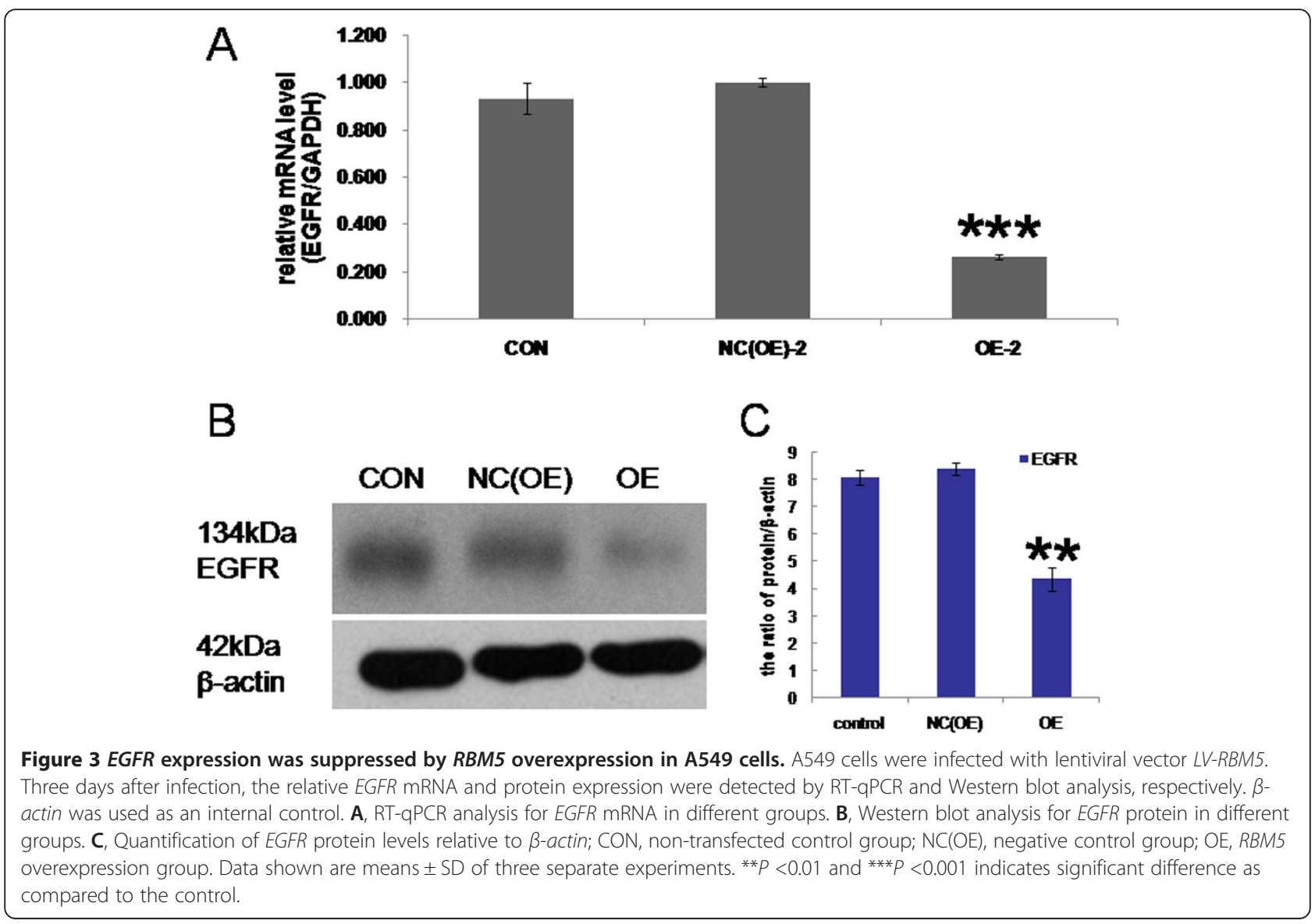




\section{A}
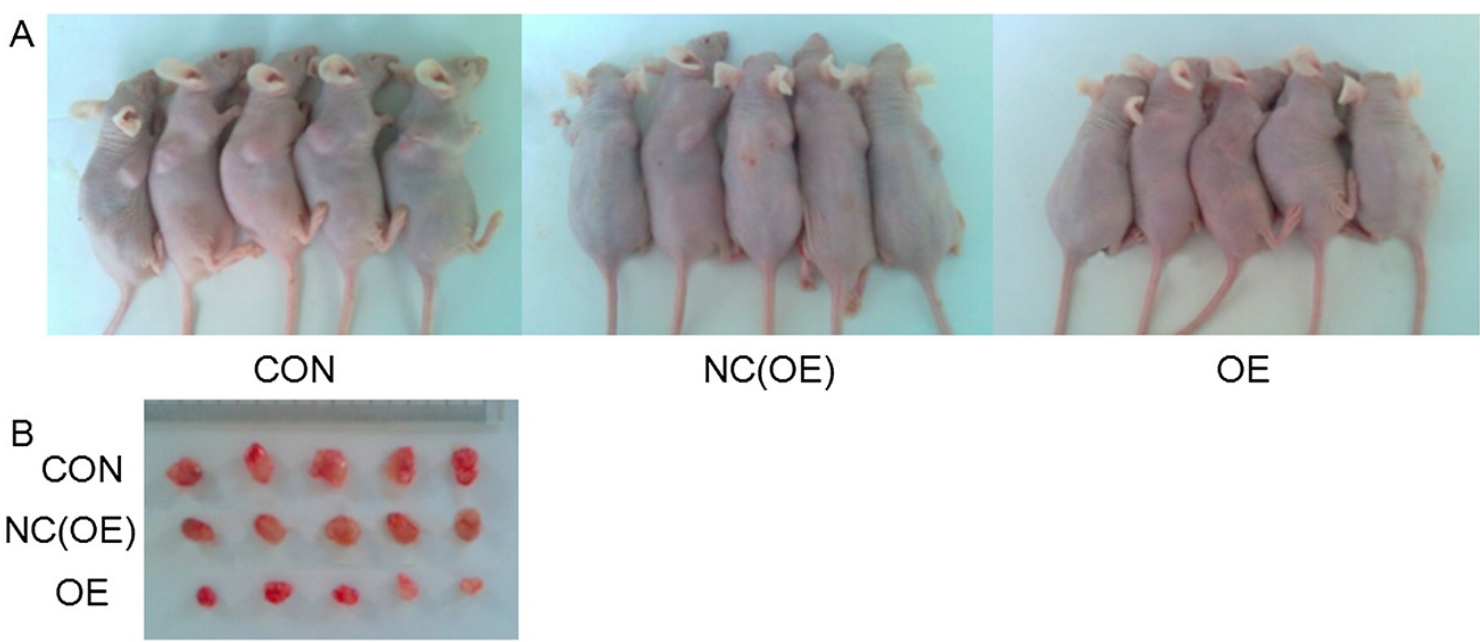

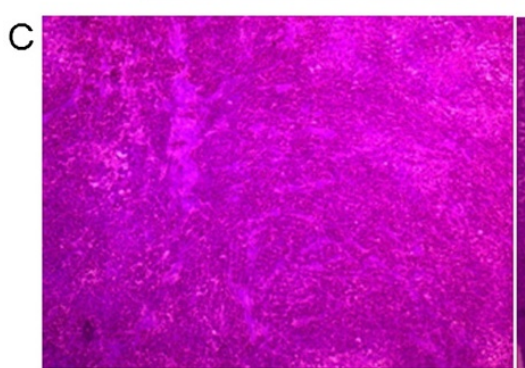

CON

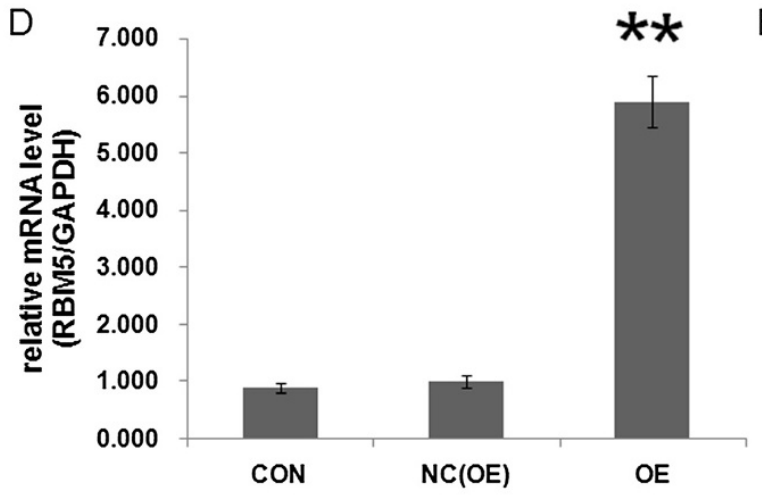

$\mathrm{F}$

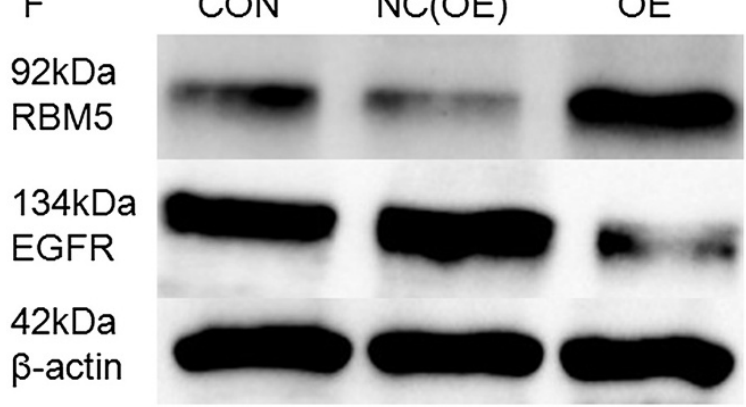

E
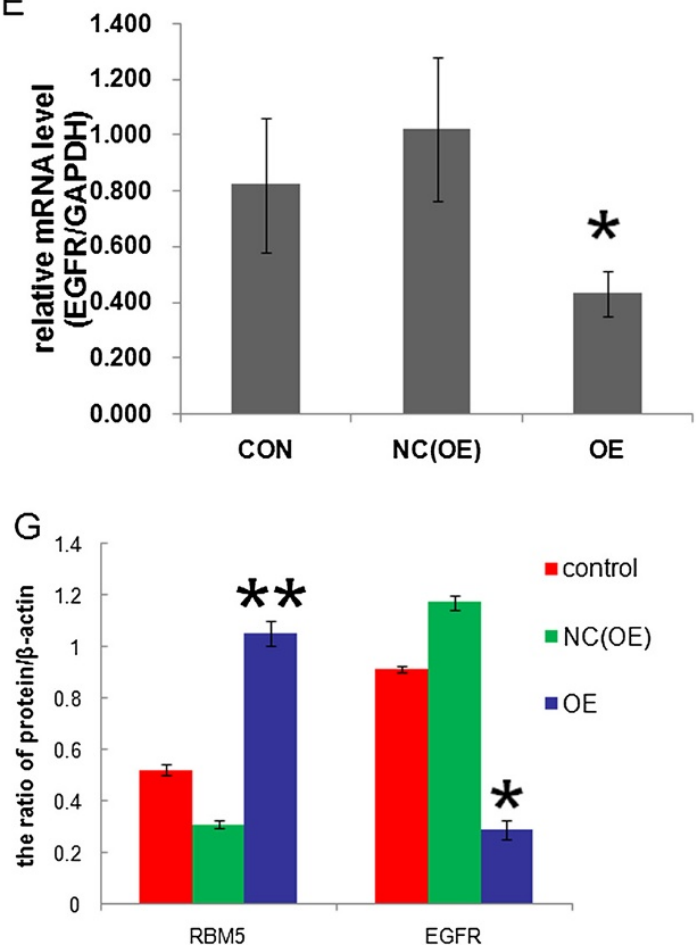

Figure 4 (See legend on next page.) 
(See figure on previous page.)

Figure 4 EGFR expression was suppressed by RBM5 overexpression in A549 xenograft tumors. A549 xenografts were established and the RBM5 gene was delivered into xenografts by attenuated Salmonella. The mice were sacrificed on day 42 . (A) Tumor sizes in nude mice in different groups. (B) Comparision of A549 xenografts taken out from different groups. (C) H\&E staining of tumors of nude mice in different groups (40x). (D) RT-PCR analysis of the expression of relative RBM5 mRNA in the xenograft tumors. (E) RT-PCR analysis of the expression of relative EGFR mRNA in the xenograft tumors. (F) Western blot analysis of RBM5 and EGFR protein expression in the xenograft tumors. (G) Quantification of protein expression relative to $\beta$-actin. $\beta$-actin was used as an internal control. CON, non-transfected control group; NC(OE), negative control group; OE, RBM5 overexpression group. Data shown are means $\pm \mathrm{SD}$ of three separate experiments. ${ }^{*} P<0.05$ and ${ }^{* *} P<0.01$ indicate significant difference as compared to the negative control.

showed that there were a large number of cancer nests in control, and that the tumor tissue could survive in a good state (Figure 4).

\section{Discussion}

The RBM5 gene is a tumor suppressor gene (TSG) that is located within a $370 \mathrm{~kb}$ overlapping lung cancer allelic loss region on 3p21.3 [24]. There is increasing evidence suggesting that downregulation of RBM5 plays an important role in NSCLC occurrence, progression, metastasis, and drug resistance $[16,18,21,22,25,26]$, yet the mechanisms are still not well clarified. Present studies on RBM5 anti-tumor mechanisms are mostly focused on its apoptosis induction role, such as: RBM5 overexpression enhanced TRAIL-, TNF-alpha-, Fas-, and P53-mediated apoptosis [20,27,28], increased the expression of Stat5b, BMP5 [29], Bax [17], and proapoptotic Casp-2 L [30], and decreased the expression of Amplified In Breast Cancer 1 (AIB1), proto-oncogene Pim-1, caspase antagonist BIRC3 (cIAP-2, MIHC), and cyclin-dependent kinase 2 (CDK2) [29]. Rac1 and $\beta$-catenin were upregulated when RBM5 was knocked down [26]. Our previous study confirmed previous findings and further demonstrated that exogenous expression of RBM5 inhibited the A549 cell growth in vivo and in vitro, and re-sensitized A549/DDP cells to cisplatin by enhancement of mitochondria apoptosis $[18,19,21]$. Our recent study demonstrated for the first time an inverse correlation between the expression levels of RBM5, and transforming growth factor alpha (TGF- $\alpha$ ) signaling factors, EGFR, and KRAS in NSCLC tissues [22], which suggested that the presence of a complex regulatory network between those genes was involved in tumor suppression and oncogenic expression. Although several studies found that the molecular mechanism of RBM5 tumor suppression involved cell proliferation inhibition $[17,29,31]$, the precise mechanisms underlying such inhibition have been poorly understood. Here, we demonstrate that overexpression of RBM5 suppressed EGFR expression, both in lung adenocarcinoma cell line A549 cells and in A549 xenograft tumors. This effect occurs in NSCLC cells expressing a lower level of RBM5 [17]. Previously, we have proved that $R B M 5$ expression was not directly regulated by EGFR [23], however, the results in the current study indicate that $R B M 5$ might manipulate EGFR expression as an upstream gene, which may be a predominant mechanism by which $R B M 5$ mediates tumor suppression.

Bonnal et al. found that RBM5 was a component of complexes involved in $3^{\prime}$ splice site recognition, and regulates alternative splicing of apoptosis-related genes, including the Fas receptor, switching between isoforms with antagonistic functions in programmed cell death [28]. It may be the same mechanism that explains how EGFR expression was suppressed by overexpression of RBM5. That is, upregulated RBM5 recognized the 3' splice site of the pre-mRNAs of EGFR and led to more alternatively spliced mRNAs and less matured mRNAs of EGFR. However, we could not definitively conclude what the alternatively spliced mRNAs are. The alternatively spliced mRNAs might be mRNAs of other genes, generate protein isoforms of the same gene which harbor different functions, or degenerated.

For many years, chemotherapy has been the standard first-line systemic treatment for advanced NSCLC, but the clinical outcomes were unpromising. The advent of EGFR tyrosine kinase inhibitors (TKIs) changed the treatment paradigm. Nevertheless, the clinical application is restricted by limitations [8-14], including: (1) patients should be selected on the basis of EGFR mutations rather than EGFR amplification or overexpression; and (2) primary or acquired drug resistance after a short time of usage. Previous studies found that in tumor biopsy samples, 55 to $61 \%$ of the samples were EGFR-positive and 32 to $45 \%$ had EGFR amplification, without fully overlapping each other [32-34]. Yet, the occurrence of EGFR gene mutations was only 10 to $40 \%$ [35-38]. Our present findings suggest that overexpression of RBM5 could inhibit EGFR expression by either direct or indirect ways in A549 cells. The cell line A549 was chosen for this study not only because it has the lowest RBM5 expression in seven different lung cancer cell lines [17], but also because it has wild-type EGFR-positive expression and gene amplification $[39,40]$, which are more common in NSCLC. It might be concluded that NSCLC with EGFR-positive expression or gene amplification could be treated by exogenous $R B M 5$, resulting in EGFR suppression. Our results could have a potential implication for lung cancer treatment, and uncover a 
new promising therapeutic strategy to suppress the EGFR pathway, which is induced by the overexpression of RBM5. Taken together, our study demonstrates a prospective meaning that overexpression of RBM5 in NSCLCs would lead to tumor suppression through EGFR inhibition. $R B M 5$ may act as a novel therapeutic target in terms of gene therapy.

Nevertheless, there were still several limitations in the present study. Firstly, as we have focused on the A549 cell line, additional experiments involving other cancer cell lines or normal and/or immortalized cell lines would help to verify this relationship between these two genes. Secondly, as the upstream regulation of EGFR is still not well understood, further studies concerning whether there are other mechanisms involving in this process are warranted in order to confirm the specific mechanisms of EGFR expression suppression. Thirdly, the relationship between RBM5 and EGFR mutation is yet unknown. Further investigation is required to determine whether $R B M 5$ is able to modulate EGFR expression when EGFR mutations exist.

\section{Conclusions}

We demonstrate that EGFR expression is regulated by RBM5 in vivo and in vitro in a direct or indirect way, and that may be one of the predominant mechanisms by which $R B M 5$ mediated tumor suppression. These findings also indicate that $R B M 5$ is the upstream regulator of the EGFR pathway.

\section{Abbreviations \\ RBM5: RNA binding motif 5; EGFR: epidermal growth factor receptor; NSCLC: non-small cell lung cancer; RPMI: Roswell Park Memorial Institute; GFP: green fluorescence protein; LV-RBM5: Recombined pGC-LV-GV287-GFP vector with the RBM5 (NM_005778) gene; LV-GV287: pGC-LV-GV287-GFP with a scrambled control sequence; $\mathrm{MOI}$ : multiplicity of infection; p.f.u.: plaque-forming units; RT-qPCR: real-time quantitative polymerase chain reaction; CFU: colony- forming units; TBST: tris-buffered saline and Tween-20 solution; GAPDH: glyceraldehyde-3-phosphate dehydrogenase; SD: standard deviation; TSG: tumor suppressor gene; TKls: tyrosine kinase inhibitors.}

\section{Competing interests}

The authors declare that they have no competing interests.

\section{Authors' contributions}

ZZS performed all the experiments and drafted the manuscript. JZY and RWL participated in the RNA and protein extraction. $H L$ and $J Z$ participated in the data analysis. KW contributed to the research design, data collection, and interpretation. KW oversaw the design of the study, and was involved in critically revising the manuscript. All authors have read and approved the final version of the manuscript.

\section{Acknowledgements}

This study was supported by grants from the National Natural Science Foundation of China (number: 81071919), Norman Bethune Program of Jilin University (number: 2012220) and the Provincial Training Program of Science and Technology for Innovative Talents of Jilin (number: 20130521002JH) for KW.

\section{Author details}

${ }^{1}$ Department of Respiratory Medicine, The Second Affiliated Hospital of Jilin University, No.218 Ziqiang Street, Nanguan District, Changchun, Jilin 130041,
China. ${ }^{2}$ Department of Pathophysiology, Norman Bethune College of Medicine of Jilin University, No.126 Xinmin Street, Chaoyang District, Changchun, Jilin 130021, China. ${ }^{3}$ Department of Urinary Surgery, The Second Affiliated Hospital of Jilin University, No.218 Ziqiang Street, Nanguan District, Changchun, Jilin 130041, China. ${ }^{4}$ Department of Respiratory Medicine, Changchun General Hospital, No.1810 Renmin Street, Nanguan District, Changchun, Jilin 130021, China.

Received: 26 August 2014 Accepted: 18 November 2014 Published: 2 December 2014

\section{References}

1. Siegel R, Ma J, Zou Z, Jemal A: Cancer statistics, 2014. CA Cancer J Clin 2014, 64:9-29.

2. DeSantis $C E$, Lin CC, Mariotto $A B$, Siegel RL, Stein $K D$, Kramer JL, Alteri $R$, Robbins AS, Jemal A: Cancer treatment and survivorship statistics, 2014. CA Cancer J Clin 2014, 64:252-271.

3. Wang $L$, Xiong $Y$, Sun $Y$, Fang $Z$, Li L, Ji H, Shi T: HLungDB: an integrated database of human lung cancer research. Nucleic Acids Res 2010, 38:D665-D669.

4. Wei Y, Zou Z, Becker N, Anderson M, Sumpter R, Xiao G, Kinch L, Koduru P, Christudass CS, Veltri RW, Grishin NV, Peyton M, Minna J, Bhagat G, Levine B: EGFR-mediated Beclin 1 phosphorylation in autophagy suppression, tumor progression, and tumor chemoresistance. Cell 2013, 154:1269-1284.

5. Salomon DS, Brandt R, Ciardiello F, Normanno N: Epidermal growth factor-related peptides and their receptors in human malignancies. Crit Rev Oncol Hematol 1995, 19:183-232.

6. Read RD, Cavenee WK, Furnari FB, Thomas JB: A drosophila model for EGFR-Ras and PI3K-dependent human glioma. PLoS Genet 2009, 5:e1000374.

7. Pennock S, Wang Z: Stimulation of cell proliferation by endosomal epidermal growth factor receptor as revealed through two distinct phases of signaling. Mol Cell Biol 2003, 23:5803-5815.

8. Passaro A, Gori B, De Marinis F: Afatinib as first-line treatment for patients with advanced non-small-cell lung cancer harboring EGFR mutations: focus on LUX-Lung 3 and LUX-Lung 6 phase III trials. J Thorac Dis 2013, 5:383-384.

9. Rosell R, Carcereny E, Gervais R, Vergnenegre A, Massuti B, Felip E, Palmero R, Garcia-Gomez R, Pallares C, Sanchez JM, Porta R, Cobo M, Garrido P, Longo F, Moran T, Insa A, De Marinis F, Corre R, Bover I, Illiano A, Dansin E, de Castro J, Milella M, Reguart N, Altavilla G, Jimenez U, Provencio M, Moreno MA, Terrasa J, Muñoz-Langa J, et al: Erlotinib versus standard chemotherapy as first-line treatment for European patients with advanced EGFR mutation-positive non-small-cell lung cancer (EURTAC): a multicentre, open-label, randomised phase 3 trial. Lancet Oncol 2012, 13:239-246.

10. Han JY, Park K, Kim SW, Lee DH, Kim HY, Kim HT, Ahn MJ, Yun T, Ahn JS, Suh C, Lee JS, Yoon SJ, Han JH, Lee JW, Jo SJ, Lee JS: First-SIGNAL: first-line singleagent iressa versus gemcitabine and cisplatin trial in never-smokers with adenocarcinoma of the lung. J Clin Oncol 2012, 30:1122-1128.

11. Zhou C, Wu YL, Chen G, Feng J, Liu XQ, Wang C, Zhang S, Wang J, Zhou S, Ren S, Lu S, Zhang L, Hu C, Hu C, Luo Y, Chen L, Ye M, Huang J, Zhi X, Zhang Y, Xiu Q, Ma J, Zhang L, You C: Erlotinib versus chemotherapy as first-line treatment for patients with advanced EGFR mutation-positive non-small-cell lung cancer (OPTIMAL, CTONG-0802): a multicentre, open-label, randomised, phase 3 study. Lancet Oncol 2011, 12:735-742.

12. Mitsudomi T, Morita S, Yatabe Y, Negoro S, Okamoto I, Tsurutani J, Seto T, Satouchi M, Tada H, Hirashima T, Asami K, Katakami N, Takada M, Yoshioka H, Shibata K, Kudoh S, Shimizu E, Saito H, Toyooka S, Nakagawa K, Fukuoka M, West Japan Oncology Group: Gefitinib versus cisplatin plus docetaxel in patients with non-small-cell lung cancer harbouring mutations of the epidermal growth factor receptor (WJTOG3405): an open label, randomised phase 3 trial. Lancet Oncol 2010, 11:121-128.

13. Mok TS, Wu YL, Thongprasert S, Yang CH, Chu DT, Saijo N, Sunpaweravong P, Han B, Margono B, Ichinose Y, Nishiwaki Y, Ohe Y, Yang JJ, Chewaskulyong B, Jiang $H$, Duffield EL, Watkins CL, Armour AA, Fukuoka M: Gefitinib or carboplatin-paclitaxel in pulmonary adenocarcinoma. N Engl J Med 2009, 361:947-957.

14. Hrustanovic G, Lee BJ, Bivona TG: Mechanisms of resistance to EGFR targeted therapies. Cancer Biol Ther 2013, 14:304-314.

15. Timmer $T$, Terpstra $P$, van den Berg A, Veldhuis PM, Ter Elst A, van der Veen AY, Kok K, Naylor SL, Buys CH: An evolutionary rearrangement of the 
Xp11.3-11.23 region in 3p21.3, a region frequently deleted in a variety of cancers. Genomics 1999, 60:238-240.

16. Oh JJ, West AR, Fishbein MC, Slamon DJ: A candidate tumor suppressor gene, H37, from the human lung cancer tumor suppressor locus 3p21.3. Cancer Res 2002, 62:3207-3213.

17. Oh JJ, Razfar A, Delgado I, Reed RA, Malkina A, Boctor B, Slamon DJ: 3p21.3 tumor suppressor gene H37/Luca15/RBM5 inhibits growth of human lung cancer cells through cell cycle arrest and apoptosis. Cancer Res 2006, 66:3419-3427.

18. Shao C, Zhao L, Wang K, Xu W, Zhang J, Yang B: The tumor suppressor gene RBM5 inhibits lung adenocarcinoma cell growth and induces apoptosis. World J Surg Oncol 2012, 10:160.

19. Shao C, Yang B, Zhao L, Wang S, Zhang J, Wang K: Tumor suppressor gene RBM5 delivered by attenuated Salmonella inhibits lung adenocarcinoma through diverse apoptotic signaling pathways. World J Surg Oncol 2013, 11:123.

20. Kobayashi T, Ishida J, Musashi M, Ota S, Yoshida T, Shimizu Y, Chuma M, Kawakami H, Asaka M, Tanaka J, Imamura M, Kobayashi M, Itoh H, Edamatsu $H$, Sutherland LC, Brachmann RK: p53 transactivation is involved in the antiproliferative activity of the putative tumor suppressor RBM5. Int $\mathrm{J}$ Cancer 2011, 128:304-318.

21. Li P, Wang K, Zhang J, Zhao L, Liang H, Shao C, Sutherland LC: The 3p21.3 tumor suppressor RBM5 resensitizes cisplatin-resistant human non-small cell lung cancer cells to cisplatin. Cancer Epidemiol 2012, 36:481-489.

22. Liang H, Zhang J, Shao C, Zhao L, Xu W, Sutherland LC, Wang K. Differential expression of RBM5, EGFR and KRAS mRNA and protein in non-small cell lung cancer tissues. J Exp Clin Cancer Res 2012, 31:36.

23. Masilamani TJ, Rintala-Maki ND, Wang K, Sutherland LC: Downregulating activated epidermal growth factor receptor has no effect on RBM5 expression. Chin Med J (Engl) 2012, 125:2378-2381.

24. Lerman MI, Minna JD: The 630-kb lung cancer homozygous deletion region on human chromosome 3p21.3: identification and evaluation of the resident candidate tumor suppressor genes. The international lung cancer chromosome 3p21.3 tumor suppressor gene consortium. Cancer Res 2000, 60:6116-6133.

25. Sutherland LC, Wang K, Robinson AG: RBM5 as a putative tumor suppressor gene for lung cancer. J Thorac Oncol 2010, 5:294-298.

26. Oh JJ, Taschereau EO, Koegel AK, Ginther CL, Rotow JK, Isfahani KZ, Slamon DJ: RBM5/H37 tumor suppressor, located at the lung cancer hot spot $3 p 21.3$, alters expression of genes involved in metastasis. Lung Cancer 2010, 70:253-262.

27. Rintala-Maki ND, Sutherland LC: LUCA-15/RBM5, a putative tumour suppressor, enhances multiple receptor-initiated death signals. Apoptosis 2004, 9:475-484.

28. Bonnal S, Martinez C, Forch P, Bachi A, Wilm M, Valcarcel J: RBM5/Luca-15/ $\mathrm{H} 37$ regulates Fas alternative splice site pairing after exon definition. Mol Cell 2008, 32:81-95.

29. Mourtada-Maarabouni M, Keen J, Clark J, Cooper CS, Williams GT: Candidate tumor suppressor LUCA-15/RBM5/H37 modulates expression of apoptosis and cell cycle genes. Exp Cell Res 2006, 312:1745-1752.

30. Fushimi K, Ray P, Kar A, Wang L, Sutherland LC, Wu JY: Up-regulation of the proapoptotic caspase 2 splicing isoform by a candidate tumor suppressor, RBM5. Proc Natl Acad Sci U S A 2008, 105:15708-15713.

31. Xiao J, Li N, Xing X, He B: [Construction of RBM5 vector, establishment of stably transfected $A 549$ cell line and preliminary research on the function of RBM5 gene]. Zhong Nan Da Xue Xue Bao Yi Xue Ban 2014 39:994-1000.

32. Pinter F, Papay J, Almasi A, Sapi Z, Szabo E, Kanya M, Tamasi A, Jori B, Varkondi E, Moldvay J, Szondy K, Keri G, Dominici M, Conte P, Eckhardt S, Kopper L, Schwab R, Petak I: Epidermal growth factor receptor (EGFR) high gene copy number and activating mutations in lung adenocarcinomas are not consistently accompanied by positivity for EGFR protein by standard immunohistochemistry. J Mol Diagn 2008, 10:160-168.

33. Hirsch FR, Varella-Garcia M, Cappuzzo F, McCoy J, Bemis L, Xavier AC, Dziadziuszko R, Gumerlock P, Chansky K, West H, Gazdar AF, Crino L, Gandara DR, Franklin WA, Bunn PA Jr: Combination of EGFR gene copy number and protein expression predicts outcome for advanced non-small-cell lung cancer patients treated with gefitinib. Ann Oncol 2007, 18:752-760.
34. Li C, Sun Y, Fang Z, Han X, Fang R, Zhang Y, Pan Y, Zhang W, Ren Y, Ji H, Chen $\mathrm{H}$ : Comprehensive analysis of epidermal growth factor receptor gene status in lung adenocarcinoma. J Thorac Oncol 2011, 6:1016-1021.

35. Krawczyk P, Ramlau R, Chorostowska-Wynimko J, Powrózek T, Lewandowska MA, Limon J, Wasąg B, Pankowski J, Kozielski J, Kalinka-Warzocha E, Szczęsna A, Wojas-Krawczyk K, Skroński M, Dziadziuszko R, Jaguś P, Antoszewska E, Szumiło J, Jarosz B, Woźniak A, Jóźwicki W, Dyszkiewicz W, Pasieka-Lis M, Kowalski DM, Krzakowski M, Jassem J, Milanowski J: The efficacy of EGFR gene mutation testing in various samples from non-small cell lung cancer patients: a multicenter retrospective study. J Cancer Res Clin Oncol 2014 [Epub ahead of print].

36. Locatelli-Sanchez M, Couraud S, Arpin D, Riou R, Bringuier PP, Souquet PJ: Routine EGFR molecular analysis in non-small-cell lung cancer patients is feasible: exons 18-21 sequencing results of 753 patients and subsequent clinical outcomes. Lung 2013, 191:491-499.

37. Hwang KE, Kwon SJ, Kim YS, Park DS, Kim BR, Yoon KH, Jeong ET, Kim HR: Effect of simvastatin on the resistance to EGFR tyrosine kinase inhibitors in a non-small cell lung cancer with the T790M mutation of EGFR. Exp Cell Res 2014, 323:288-296.

38. Noronha V, Prabhash K, Thavamani A, Chougule A, Purandare N, Joshi A, Sharma R, Desai S, Jambekar N, Dutt A, Mulherkar R: EGFR mutations in Indian lung cancer patients: clinical correlation and outcome to EGFR targeted therapy. PLoS One 2013, 8:e61561.

39. He S, Yin T, Li D, Gao X, Wan Y, Ma X, Ye T, Guo F, Sun J, Lin Z, Wang Y: Enhanced interaction between natural killer cells and lung cancer cells: involvement in gefitinib-mediated immunoregulation. J Transl Med 2013, 11:186.

40. Lauand C, Rezende-Teixeira P, Cortez BA, Niero EL, Machado-Santelli GM: Independent of ErbB1 gene copy number, EGF stimulates migration but is not associated with cell proliferation in non-small cell lung cancer. Cancer Cell Int 2013, 13:38.

doi:10.1186/1477-7819-12-367

Cite this article as: Su et al:: Lentiviral vector-mediated RBM5

overexpression downregulates EGFR expression in human non-small cell lung cancer cells. World Journal of Surgical Oncology 2014 12:367.

\section{Submit your next manuscript to BioMed Central and take full advantage of:}

- Convenient online submission

- Thorough peer review

- No space constraints or color figure charges

- Immediate publication on acceptance

- Inclusion in PubMed, CAS, Scopus and Google Scholar

- Research which is freely available for redistribution 